\title{
Pilomatrix Carcinoma of the Antecubitum
}

\author{
Michael D. Eckhoff ${ }^{1}$, Joshua Tadlock ${ }^{1}$, Lisa A. Kafchinski ${ }^{2}$ \\ 1. Orthopedics, Texas Tech University Health Sciences Center El Paso, Paul L. Foster School of Medicine, El Paso, USA 2. \\ Orthopedics, Texas Tech University Health Sciences Center El Paso, El Paso, USA
}

Corresponding author: Michael D. Eckhoff, eckho048@gmail.com

\begin{abstract}
We present the case of a 46-year-old male with atypically large left elbow pilomatrix carcinoma present for 10 years with emergent excision after developing life-threatening hemorrhage. Pilomatrix carcinoma is a dermal-based malignant tumor typically of the head and neck region. Histopathology shows islands of basaloid cells, shadow cells, and fibromyxoid fibroma. Reoccurrence is seen in $23 \%$ of cases on an average of six months after primary excision. The current standard of care is wide excision with close follow-up.
\end{abstract}

Categories: Dermatology, Oncology, Orthopedics

Keywords: pilomatrix carcinoma, tumor surgery, orthopedic oncology

\section{Introduction}

Pilomatrix carcinoma is a rare, low-grade, malignant skin tumor of the hair matrix initially described in 1980 with approximately 125 cases reported in the literature [1-4]. It is related to pilomatrixoma, a common benign skin tumor. Pilomatrix carcinoma is characterized by a slow growth, firm, mobile nodule often misdiagnosed on initial evaluation $[2,5]$. They typically occur in middle-aged white males in the head and neck region, although there are several reported cases arising in extremities [3,4,6-9]. When caught early, these lesions are often treated by a dermatologist with Mohs surgery [10-12].

Histologically, these demonstrate poorly circumscribed tumors with basaloid and "ghost" cells and frequent metastases $[1,13]$. The immunohistopathologic analysis demonstrates mutations in CTNNB1, a $\beta$-catenin gene $[14,15]$. Rarely these tumors will show sarcomatoid features as well [9]. The recurrence rate is high with $23 \%$ after wide excision, and with metastasis occurring in $13 \%[3,16]$.

Our case demonstrates a patient with an exophytic mass to the upper extremity with uncontrolled hemorrhage and local reoccurrence within four months of initial excision.

\section{Case Presentation}

Received 01/16/2020

Review began 01/21/2020 Review ended 01/28/2020 Published 01/30/2020

○ Copyright 2020

Eckhoff et al. This is an open access article distributed under the terms of the Creative Commons Attribution License CC-BY 3.0., which permits unrestricted use, distribution, and reproduction in any medium, provided the original author and source are credited.

A 46-year-old male presented with a greater than 10-year history of a left arm wound. He initially developed a wound on his left antecubital region after a spider bite. The wound that developed nearly healed before becoming increasingly friable, vascularized, and enlarging. Starting about $1 \mathrm{~cm}$ in diameter it progressed to $15 \times 12 \mathrm{~cm}$ in size with the greatest growth in six months prior to excision. On evaluation by the senior author, it was foul smelling, painful, draining fluid, and bled easily. His preoperative MRIs are shown in Videos 1,2. The patient was scheduled for surgery 10 days later. Five days later, however, the patient presented to the emergency department with uncontrolled hemorrhage from the lesion, necessitating tourniquet application, multiunit transfusions, and emergent surgical excision. Figures 1,2 show the images obtained immediately prior to excision.

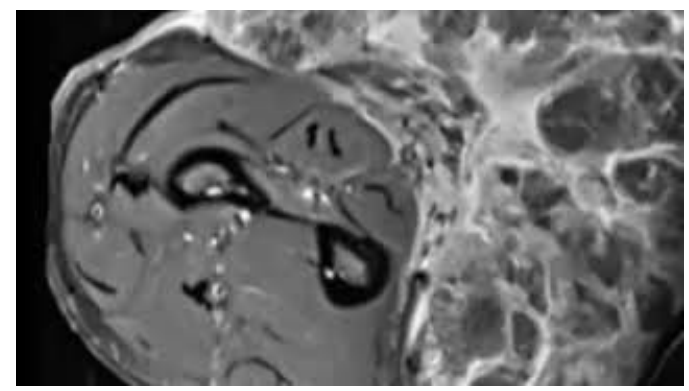

\section{VIDEO 1: Axial T2 with contrast}

Preoperative axial T2 MRI with contrast demonstrating heterogeneous components with septations

View video here: https://youtu.be/4aS1QrBn6J0 


\section{Cureus}

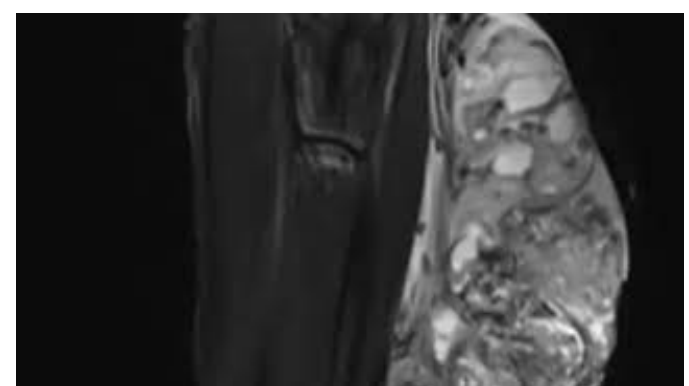

VIDEO 2: Sagittal T2 MRI preoperatively

Preoperative T2 MRI of arm demonstrating exophytic mass with T2 enhancement of heterogeneous components

View video here: https://youtu.be/wWVYPUkUfRQ 


\section{Cureus}

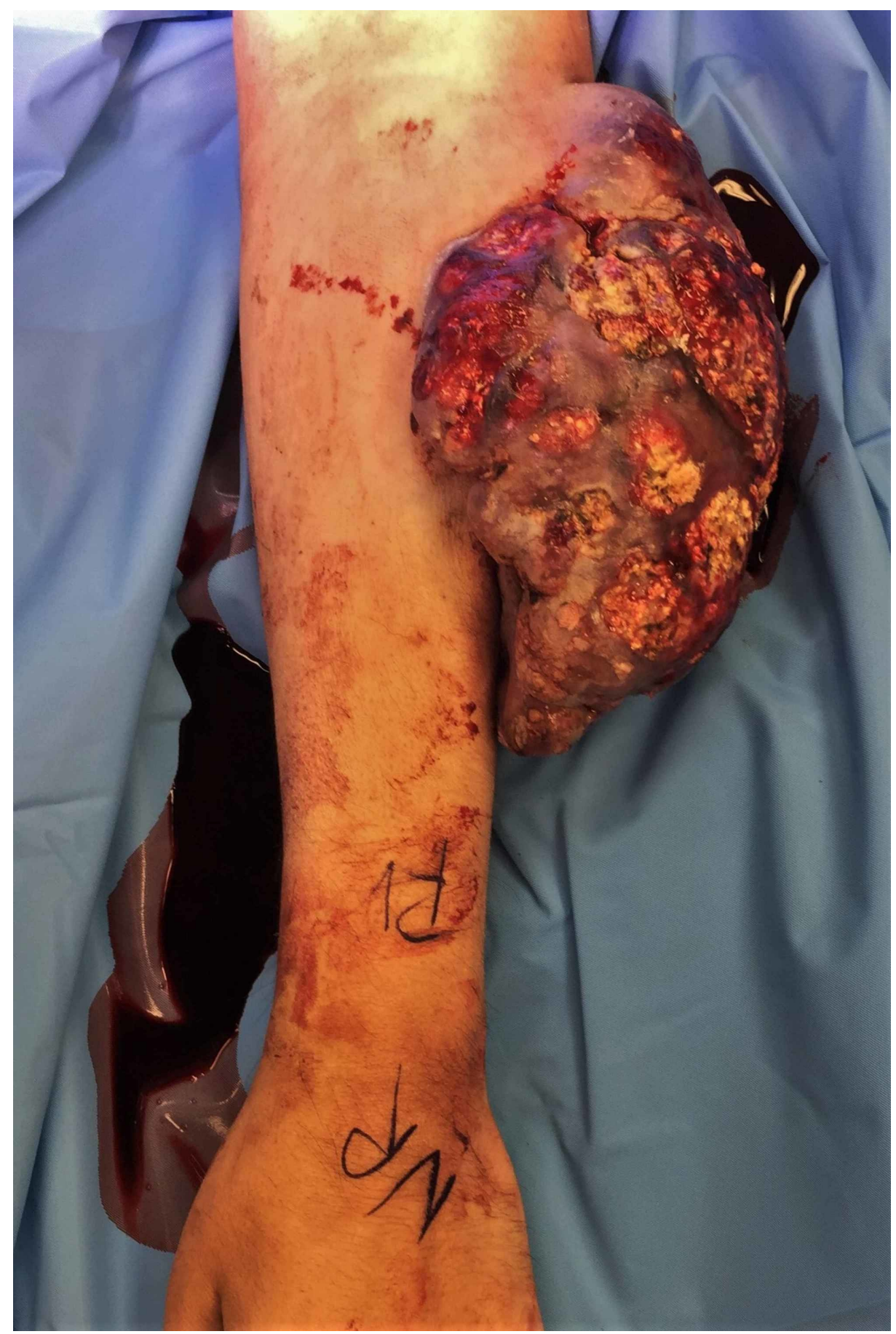

\section{FIGURE 1: Preoperative image}

Preop image of patient's arm with exophyic mass over antebrachium 


\section{Cureus}

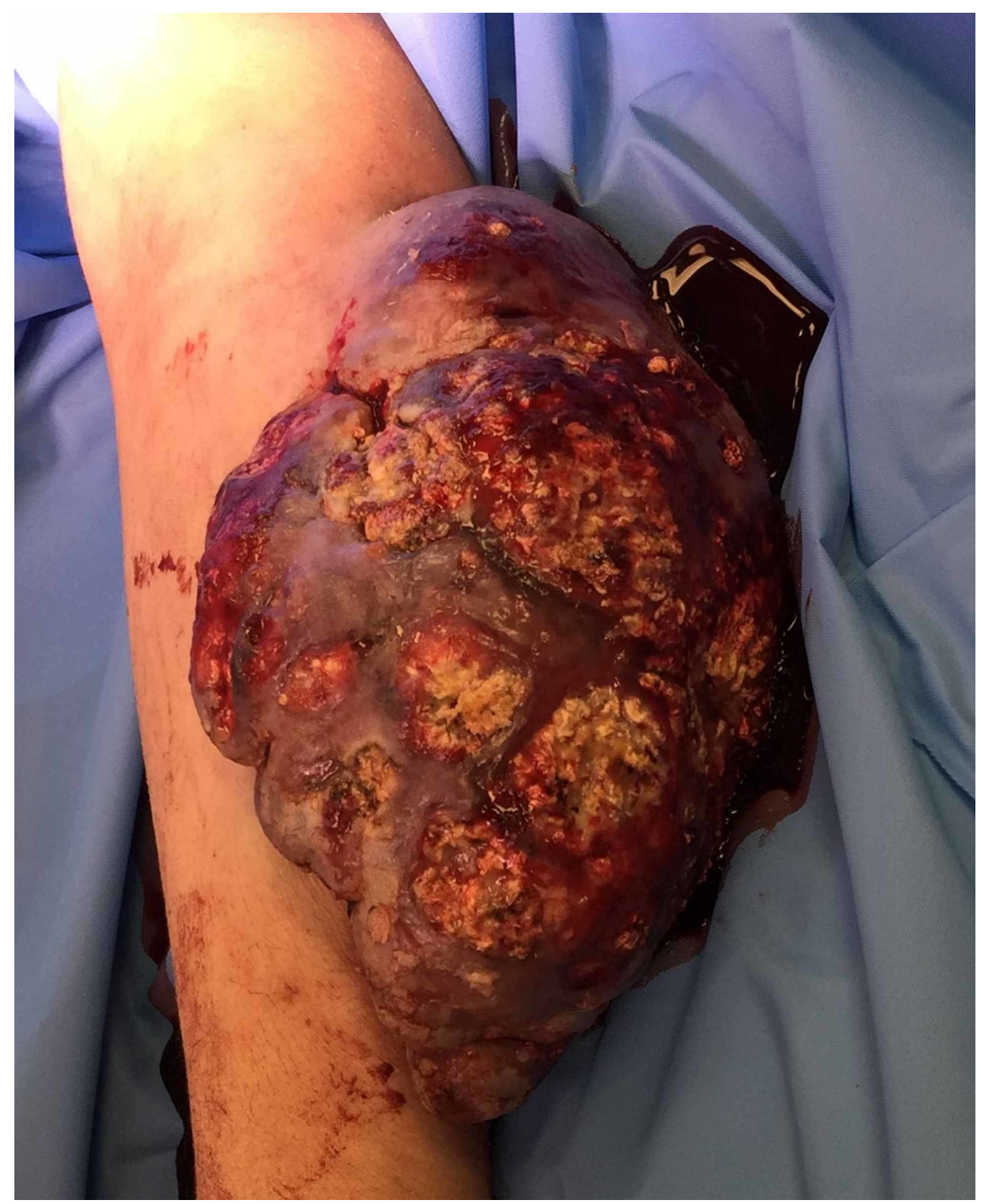

FIGURE 2: Close up of exophytic mass

Closer image of preoperative patient's arm with exophytic mass

After the index excision, the patient required additional irrigation and debridement on postoperative day (POD) 3. His skin defect was left uncovered pending final pathology. The patient returned for limited tumor bed re-excision to obtain $5 \mathrm{~mm}$ margins and placement of biologic dressing in anticipation of splitthickness skin grafting (STSG) on POD 12. Negative margins were obtained with a re-excision surgery. He subsequently underwent STSG, which he healed without incident.

Pathologic review of the initial excised mass demonstrated extensive areas of necrosis and hemorrhage with focal areas of myxoid and cystic degeneration. Microscopic examination was remarkable for an increased mitotic index, and desmoplastic and lymphovascular invasion. These findings are consistent with pilomatrix carcinoma.

Seven months after resection, the patient presented with a three-month history of left antecubital mass that was $2 \times 4 \mathrm{~cm}$ and growing. MRI and positron emission tomography (PET) scan were obtained demonstrating left antecubital lesion with the involvement of cephalic vein and avid on PET scan. These are shown in Videos 3-5. A clinical photo of his arm is shown in Figure 3 after healing his skin graft from the initial surgery, but before excision of the reoccurrence. No distant metastases were identified. One month later, the patient underwent surgical excision of the new lesion with primary closure. Pathologic review at this time was also consistent with pilomatrix carcinoma. The patient healed from this procedure without incident. At the time of publication, the patient was 24 months out from index procedure without evidence of new reoccurrence or metastasis. 


\title{
Cureus
}

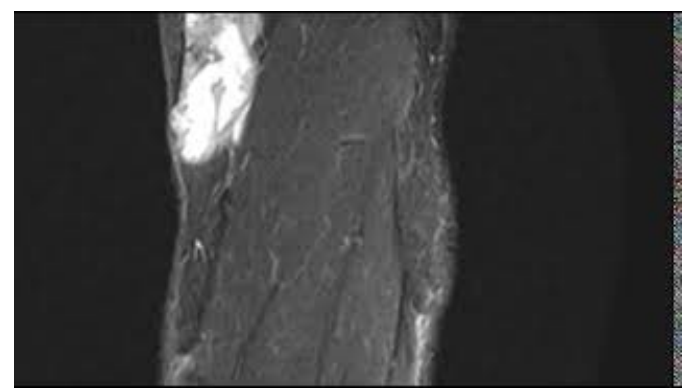

\section{VIDEO 3: Sagittal T2 MRI of local reoccurrence}

Sagittal T2 weighted MRI of local reoccurrence demonstrating similar appearance as the original tumor

View video here: https://youtu.be/Jgm3g419I7o

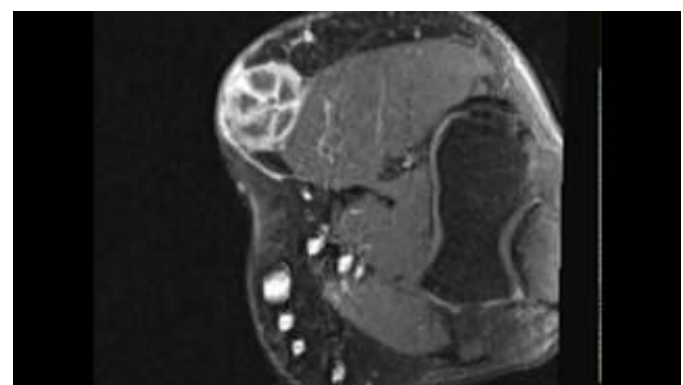

\section{VIDEO 4: Axial T2 MRI of local reoccurrence}

Axial T2 weighted MRI of local reoccurrence demonstrating similar appearance as initial tumor

View video here: https://youtu.be/AEgsAllUjpc

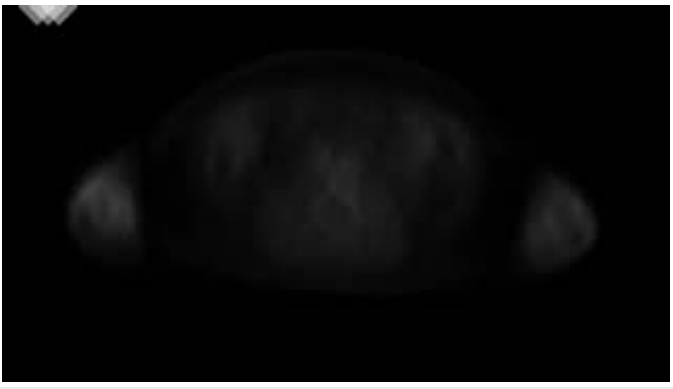

\section{VIDEO 5: PET/CT of reoccurrence}

PET/CT scan of the patient after reoccurrence demonstrating increased uptake in the left arm. The video shows from the level of the stomach to the bladder. On the right side of the video (patient's left arm) you can see an area of increased uptake from the local reoccurrence of pilomatrix carcinoma.

PET, positron emission tomography

\author{
View video here: https://youtu.be/BFLOzugvJoQ
}




\section{Cureus}

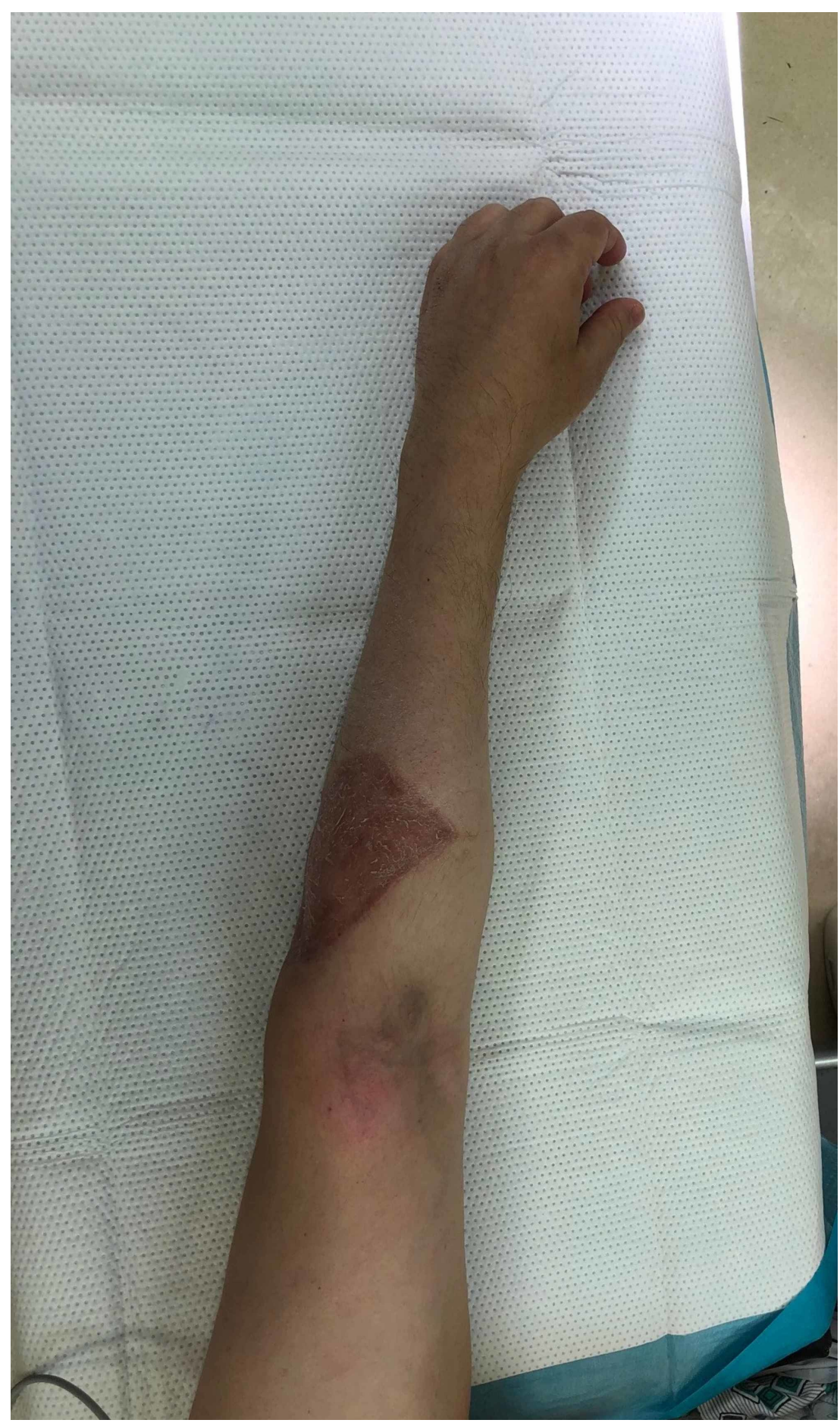

FIGURE 3: Preop image before local reoccurrence removal

\section{Discussion}

Pilomatrix carcinoma is a skin-based malignant tumor often appearing on the head and neck region in adult males. These tumors are exceptionally rare. This paper discusses an interesting case with a presentation in the antecubitum requiring emergent surgical excision and subacute local reoccurrence.

Our patient's tumor had characteristics consistent with what has been previously described. However, the tumor was quite large, measuring $12 \times 15 \mathrm{~cm}$, where the average in a study by Herrmann et al. was $3.8 \mathrm{~cm}$ in diameter, although there were samples up to $20 \mathrm{~cm}$ in size [3]. The percentage of these tumors to

reoccur locally is $23 \%$ and as metastatic lesions in $13 \%$ of patients. The average time to reoccurrence has been found to be six months, even when appropriate wide excision of $2-3 \mathrm{~cm}$ is performed. This time frame was consistent with our case. Fortunately, our patient has not shown evidence of metastasis at 24-month follow-up. 
Additionally, these tumors are highly vascular; however, vascularity does not guide the treatment course for these tumors [17]. In most described cases, the tumors are friable and bleed easily. Our patient's tumor had significant enough vasculature that life-threatening hemorrhage occurred requiring tourniquet application, transfusion, and emergent surgical excision to control.

The pathologic review of the tumor demonstrated extensive necrosis with focal areas of myxoid stroma, cystic degeneration, high mitotic index, and invasion into desmoplastic and lymphovascular structures. This is consistent with previous studies demonstrating islands of basaloid cells, areas of necrosis, shadow cells, and fibromyxoid stroma. Pilomatrix carcinoma is differentiated from a pilomatrixoma by the amount of nuclear pleomorphism, mitotic atypia, and local invasion of neural and vascular elements $[2,8,10,13]$.

Current standard of care is wide resection with margins of 5-30 mm $[11,13,14]$. When the lesion is identified early, there is good evidence for successful treatment with Mohs surgery as the average size is $3.8 \mathrm{~cm}$ in diameter [10-12]. After treatment, these patients need close follow-up due to the relatively high risk of local reoccurrence and metastasis even with wide excision [3]. The future of care in these lesions will focus on investigating adjuvant and neoadjuvant modalities to include radiotherapy, electron-beam radiation, and chemotherapy to decrease the chance for reoccurrence $[18,19]$.

\section{Conclusions}

We presented the case of a 46-year-old male who developed an antecubital pilomatrix carcinoma, a dermalbased malignancy that is characterized by islands of basaloid cells and shadow cells. The case presented is unusual with atypically large tumor size, emergent treatment due to uncontrolled hemorrhage, and local recurrence. The patient was initially treated with emergent resection and staged tumor bed re-excision for the original tumor. He subsequently underwent excision of the local recurrence as well. Local recurrence is common after wide resection, as demonstrated in this case.

\section{Additional Information \\ Disclosures}

Human subjects: Consent was obtained by all participants in this study. Conflicts of interest: In compliance with the ICMJE uniform disclosure form, all authors declare the following: Payment/services info: All authors have declared that no financial support was received from any organization for the submitted work. Financial relationships: All authors have declared that they have no financial relationships at present or within the previous three years with any organizations that might have an interest in the submitted work. Other relationships: All authors have declared that there are no other relationships or activities that could appear to have influenced the submitted work.

\section{References}

1. Lopansri S, Mihm MC: Pilomatrix carcinoma or calcifying epitheliocarcinoma of malherbe. A case report and review of literature. Cancer. 1980, 45:2368-2373. 10.1002/1097-0142(19800501)45:9<2368::aidcncr2820450922>3.0.c0;2-b

2. Cornejo KM, Deng A: Pilomatrix carcinoma: a case report and review of the literature . Am J Dermatopathol. 2013, 35:389-394. 10.1097/DAD.0b013e318274b7da

3. Herrmann JL, Allan A, Trapp KM, Morgan MB: Pilomatrix carcinoma: 13 new cases and review of the literature with emphasis on predictors of metastasis. J Am Acad Dermatol. 2014, 71:38-43.e2. 10.1016/j.jaad.2014.02.042

4. Sato S, Nakamura Y, Shimizu M, et al.: Giant pedunculated pilomatrix carcinoma on the upper appearance limb: a rare clinical appearance. Eur J Dermatol. 2015, 25:91-92. 10.1684/ejd.2014.2476

5. Jones C, Twoon M, Ho W, Portelli M, Robertson BF, Anderson W: Pilomatrix carcinoma: 12-year experience and review of the literature. J Cutan Pathol. 2018, 45:33-38. 10.1111/cup.13046

6. Sau P, Lupton GP, Graham JH: Pilomatrix carcinoma. Cancer. 1993, 71:2491-2498. 10.1002/10970142(19930415)71:8<2491::aid-cncr2820710811>3.0.co;2-i

7. Autelitano L, Biglioli F, Migliori G, Colletti G: Pilomatrix carcinoma with visceral metastases: case report and review of the literature. J Plast Reconstr Aesthetic Surg. 2009, 62:574-577. 10.1016/j.bjps.2008.08.024

8. De Gálvez-Aranda MV, Herrera-Ceballos E, Sánchez-Sánchez P, Bosch-García RJ, Matilla-Vicente A: Pilomatrix carcinoma with lymph node and pulmonary metastasis: report of a case arising on the knee . Am J Dermatopathol. 2002, 24:139-143. 10.1097/00000372-200204000-00006

9. Fernandez-Flores A, Cassarino DS: Sarcomatoid pilomatrix carcinoma. J Cutan Pathol. 2018, 45:508-514. 10.1111/cup.13151

10. Melancon JM, Tom WL, Lee RA, Jackson M, Brian Jiang SI: Management of pilomatrix carcinoma: a case report of successful treatment with mohs micrographic surgery and review of the literature. Dermatol Surg. 2011, 37:1798-1805. 10.1111/j.1524-4725.2011.02170.x

11. Sable D, Snow SN: Pilomatrix carcinoma of the back treated by Mohs micrographic surgery . Dermatol Surg. 2004, 30:1174-1176. 10.1111/j.1524-4725.2004.30350.x

12. Xing L, Marzolf SA, Vandergriff T, Nijhawan RI: Facial pilomatrix carcinomas treated with Mohs micrographic surgery. JAAD Case Rep. 2018, 4:253-255. 10.1016/j.jdcr.2018.02.003

13. Aherne NJ, Fitzpatrick DA, Gibbons D, Armstrong JG: Pilomatrix carcinoma presenting as an extra axial mass: clinicopathological features. Diagn Pathol. 2008, 3:1-5. 10.1186/1746-1596-3-47

14. Lazar AJF, Calonje E, Grayson W, et al.: Pilomatrix carcinomas contain mutations in CTNNB1, the gene 


\section{Cureus}

encoding $\beta$-catenin. J Cutan Pathol. 2005, 32:148-157. 10.1111/j.0303-6987.2005.00267.x

15. Hassanein AM, Glanz SM: B-Catenin Expression in Benign and Malignant Pilomatrix Neoplasms . Br J Dermatol. 2004, 150:511-516. 10.1046/j.1365-2133.2004.05811.x

16. Agaiby S, Iyer K, Honda K, Mostow EN: Giant pilomatrix carcinoma in an immunosuppressed patient . J Am Acad Dermatol. 2011, 65:50-51. 10.1016/j.jaad.2010.12.024

17. Sorin T, Eluecque H, Gauchotte G, et al.: Pilomatrix carcinoma of the scalp. a case report and review of the literature. Ann Chir Plast Esthet. 2015, 60:242-246. 10.1016/j.anplas.2014.06.005

18. Miyahara H, Imayama S, Hashizume T, Takeishi M, Hori Y, Kohda H: Two cases of pilomatrix carcinoma . J Dermatol. 1990, 17:322-325. 10.1111/j.1346-8138.1990.tb01649.x

19. Arslan D, Gündüz Ş, Avci F, et al.: Pilomatrix carcinoma of the scalp with pulmonary metastasis: a case report of a complete response to oral endoxan and etoposide. Oncol Lett. 2014, 7:1959-1961.

10.3892/ol.2014.2021 